\title{
ANOMALOUS SEISMO-ACOUSTIC WAVE PROPAGATION AND DETERMINATION SOURCE OF INFRASOUND
}

\author{
Bayarsaikhan. $\mathrm{Ch}^{a)}$, Tungalag. ${ }^{a)}$, Lkhagvajav. $\mathrm{Ch}^{\text {b) }}$, Alexis Le Pichon ${ }^{c}$ \\ a) RCAG-MAS, P.O.Box-152, Ulaanbaatar-51, 13343, Mongolia \\ b) Physics and Electronics School and National University of Mongolia \\ ${ }^{c}$ CEA/DASE-LDG, BP-12, 91680, Bruyeres-Le-Chatel, France
}

\begin{abstract}
The network of infrasound stations (I34MN) in Mongolia daily registers set of infrasound from various sources besides explosions. The data from explosions in mines in region and from other sources detected since 2000 to 2009 in seismic and infrasound stations is analyzed. The analysis these signals dependence of speed distribution of sound from seasonal, wind forces and direction moreover on short distances. From detected in infrasound stations (I34MN) in year 80$90 \%$ of signals make microbaroms, the wide range of their sources is visible from the frequency analysis. From the general analysis registered seismo and acoustic signals of explosions on the seismic and infrasound networks stations miscalculate not only speeds of distribution of sounds on close distances (50-500 km), and also the speed model of atmosphere is made.
\end{abstract}

Keysword: : Seismo-acoustic, microbaroms, explosion, quarry blast, network

\section{Introduction}

Infrasound observation has recently been widely applied to clarify manmade and natural producing low-frequency acoustics in the atmosphere, such as ground coupled air waves from large earthquakes (A. Le Pichon 2003; A. Le Pichon 2006 et al.,), large bolides (P. G. Brown et al., 2002), and infrasound from accidental explosions (Evers and Haak, 2007). Infrasound technology is also important for monitoring possible nuclear explosions in the framework of the Comprehensive NuclearTest-Ban Treaty (Bedard and Georges, 2000).

One use of infrasound monitoring is to distinguish quarry blast from earthquakes. For example, the Mongolian NDC (RCAG) operates seismo-acoustic (infrasound) array with which it has identified $27.22 \%$ of the total number of seismic events ( $\sim 709$ per year) occurring on the Mongolian mining explosions. Most of these explosions are concentrated in several epicentral regions. Field surveys confirmed that some epicenters in Mongolia were at iron (ore), floured quarries and coal mines (Bayarsaikhan et al., 2005). Such discrimination of mining explosions has been an important tool for estimating the natural seismicity of specific regions.

Although infrasound observations can be used to discriminate manmade explosions from natural events, the localization of explosion sources using only infrasound data is not well developed compared to the conventional seismological location method mainly because infrasound propagation is strongly affected by dynamic atmospheric conditions. However, the location result is expected to contain error. A more advanced infrasonic source location method using ground-coupled air waves from strong earthquakes (A. Le Pichon et al., 2003) is based on solving the inverse problem with a celerity model and apparent horizontal phase velocity. A known earthquake's origin time and epicentre coordinates make it possible to refine the localization of the source regions with the measured azimuth and slowness variation in infrasonic signals. The study reported 
here presents an improved location method for explosions that generate both seismic and infrasonic signals. The method makes full use of the seismic parameters of the explosions and infrasonic estimations of travel times and azimuths. To assess the performance of the method, we collected data on ground-truth events by operating a temporary seismic station inside an open-pit coal mine, one of the most active regions generating both seismic and infrasonic signals in Mongolia. Finally, we compared the located on result with locations given by the seismological catalogue, the infrasonic-azimuth and the ground-truth information.

\section{Theoretical method}

Effective speed of sound: Infrasound wave propagation is, in first order, dependent on the composition and wind and temperature structure of the atmosphere. The effective sound speed incorporates these effects and, described by

$$
C_{\text {eff }}=\sqrt{\gamma_{g} R T}+\hat{n} \cdot \mathbf{u}
$$

where the multiplication of the ratio of specific heats with the gas constant for air is $\gamma_{g} R$ $=402.8 \mathrm{~m}^{2} \mathrm{~s}^{-2} \mathrm{~K}^{-1}$. The absolute temperature is given by $T$ and $n^{\wedge} \cdot \mathbf{u}$ projects the wind $\mathbf{u}$ in the direction from source to observer $\hat{n}$, through this inner-product. The temperature decreases with altitude in the lower atmosphere, under regular atmospheric circumstances. As a result of this, sound bends upward as function of horizontal distance. Refraction of infrasound may occur from regions where $c_{\text {eff }}$ becomes larger than its surface value and depends on the orientation of the wave-front. This can be caused by an increase in wind, or temperature, or a combined effect. Refraction follows from Snell's law and will bend infrasound back to the earth's surface. The absorption of sound in the atmosphere is a function of frequency and decreases with decreasing frequency. The propagation speed of these waves is also strongly affected by the stratospheric wind which means that the upper atmospheric winds have a dominating influence on the propaga- tion properties of these waves (1972. Donn .,Rind).

\section{Microbarographic array and data pro- cessing}

Infrasonic signals are continuously recorded by an eight element array located at Songino, in the East of Ulaanbaatar, Mongolia $\left(47.80^{\circ} \mathrm{N}\right.$ and $\left.106.41^{\circ} \mathrm{E}\right)$. The Songino (I34MN) array has been set up to characterize infrasonic sources and to improve atmospheric and propagation models. This array is a prototype $\mathrm{CTBT}^{1}$ station. The CTBT global infrasonic network will permit the detection and location of both ground surface and middle atmosphere explosions.

The array, which has an aperture of $\sim 1.5$ $\mathrm{km}$, has been operating continuously since October 2000. Development of infrasound arrays we can divide with two time range. Beginning the I34MN array, a triangular $1.5 \mathrm{~km}$ aperture array located in Tavan Tolgoi valley area, was originally installed in October, 2000 with four infrasound stations. However, it was upgraded in September 2006, by four additional infrasound stations were added in array network in order to improve automatic detection procedure. Each sensor is a MB2000 microbarograph that can measure both absolute and relative pressure. The MB2000 has been designed to operate from DC up to $27 \mathrm{~Hz}$ with an electronic noise level of $2 \mathrm{mPa} \mathrm{rms}{ }^{2}$ in the $0.02-4$ $\mathrm{Hz}$ frequency band. The sensor provides relative pressure at ground level with a sensitivity of $20 \mathrm{mV} / \mathrm{Pa}$ and a dynamic range of 134 $\mathrm{dB}$. The digitized data are sent to the central station, where they are stored in a buffer and transmitted in real time to the base geophysical laboratory over a shared VSAT satellite link. In order to minimize pressure changes due to surface wind effects, each sensor is connected to an $8 \mathrm{~m}$-diameter noise reducing system equipped to 32 inlet ports (Fig. 3). A comparison of the performance of this pipe array with completely open ports demonstrated that the

1 Comprehensive Nuclear Test Ban Treaty

2 Rms-root mean square 
pipe array with screened inlet ports reduces substantially reduces high frequencies noise (Alcoverro, 1998). For a surface wind speed of
$1 \mathrm{~m} / \mathrm{s}$ and for frequencies greater than $0.3 \mathrm{~Hz}$, this filtering system significantly improves the signal to noise ratio $(\sim 20 \mathrm{~dB}$ at $1 \mathrm{~Hz})$.

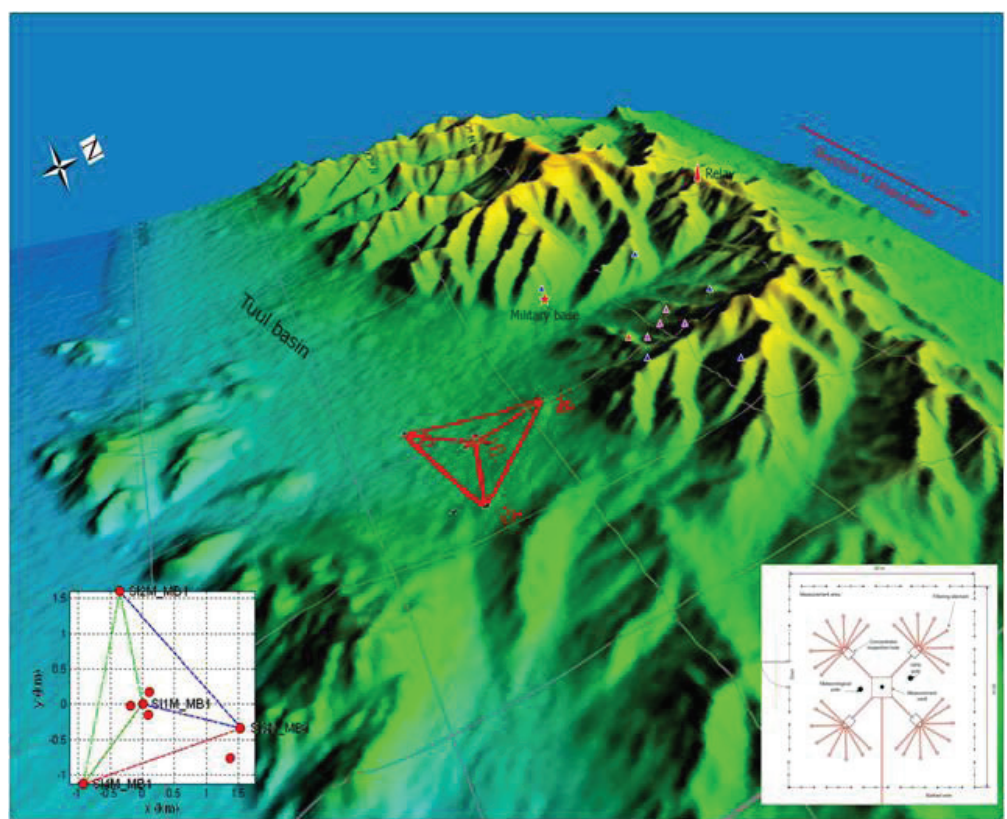

Figure 3 The microbarographic array is located at Songino $47.80^{\circ} \mathrm{N}$ and $106.41^{\circ} \mathrm{E}$. Each microbarograph is connected to an $8 \mathrm{~m}$-diameter noise reducing system.
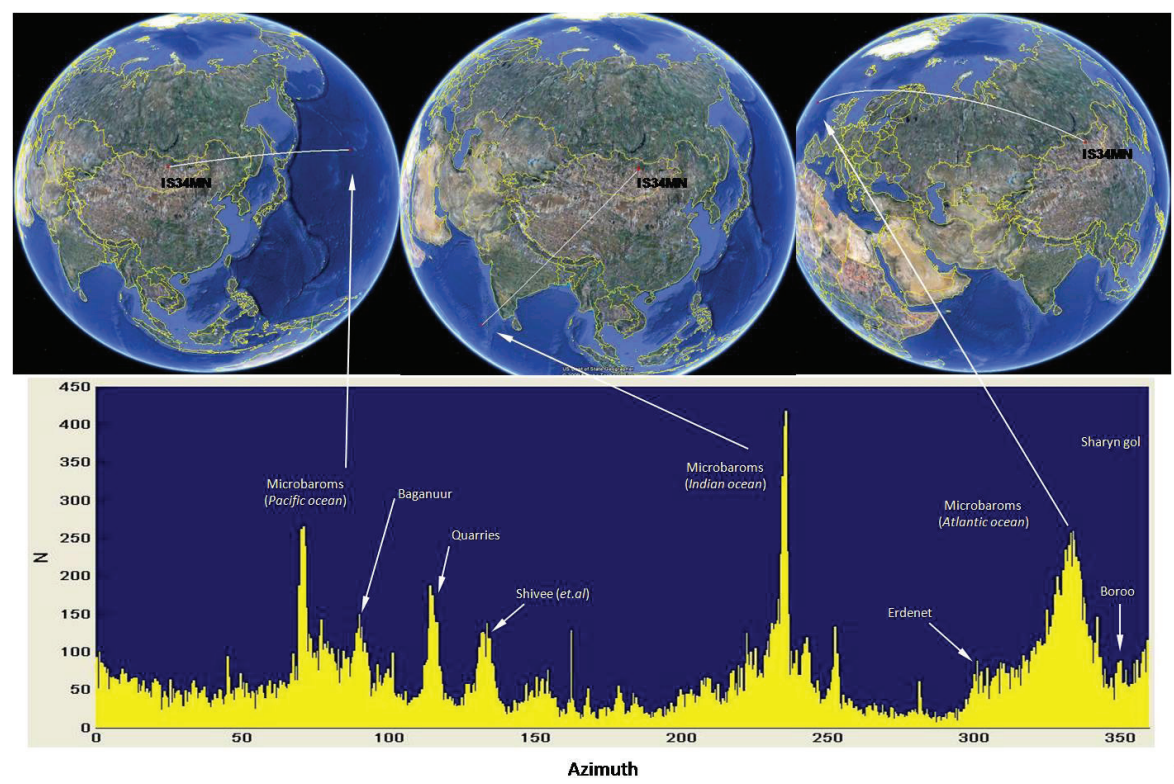

Figure 4. Regular signals are observed high frequency (1-5 Hz). Quarry blast detected by I34MN 
Determination Source of Infrasound

In during period after the installation of this station network, there have recorded explosions induced by natural's and human's sources as like microbars of India, Pacific and Atlantic ocean, seismic sound, shooting of military artillery, mining explosions, urban noise, take-off and landing of satellite plane and others. We have analyzed azimuth of signals which are recorded in infrasound stations between 2000 and 2009. It shows on the figure 4 .

The source determination gives to study a relationship of parameters, which are included direction and power of wind, infrasound distribution in atmosphere by distance related by seasonal variation. Figure 5 shows the recorded infrasound signal corresponding influence by stratosphere's wind in winter and summer time. Zonal wind direction of northern global in winter is to troposphere layer $0-10 \mathrm{~km}$ and to stratosphere layer 40-48 $\mathrm{km}$ along from west to east (W-E), and in summer time it changes along to meridian direction from South to North.

We have done detail analyses in the explosion data. By the preliminary results, there have more recorded sound wave's phases of signal in the period between December to April. In the period between May to November, there have observed that sound wave's phases of signal record decreased by influence of seasonal variation associated temperature.

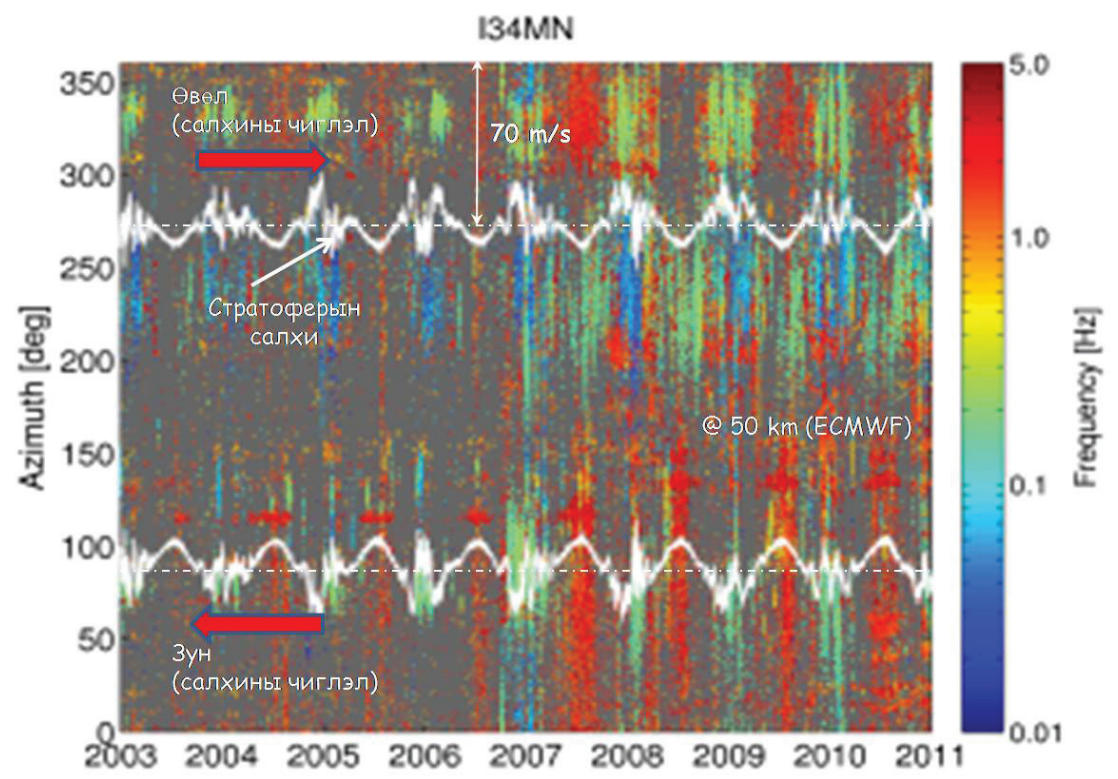

Figure 5 Single station processing PMCC analysis influence stratospheric winds. (9 years automatic processing at the I34MN: 100.284 detections) 


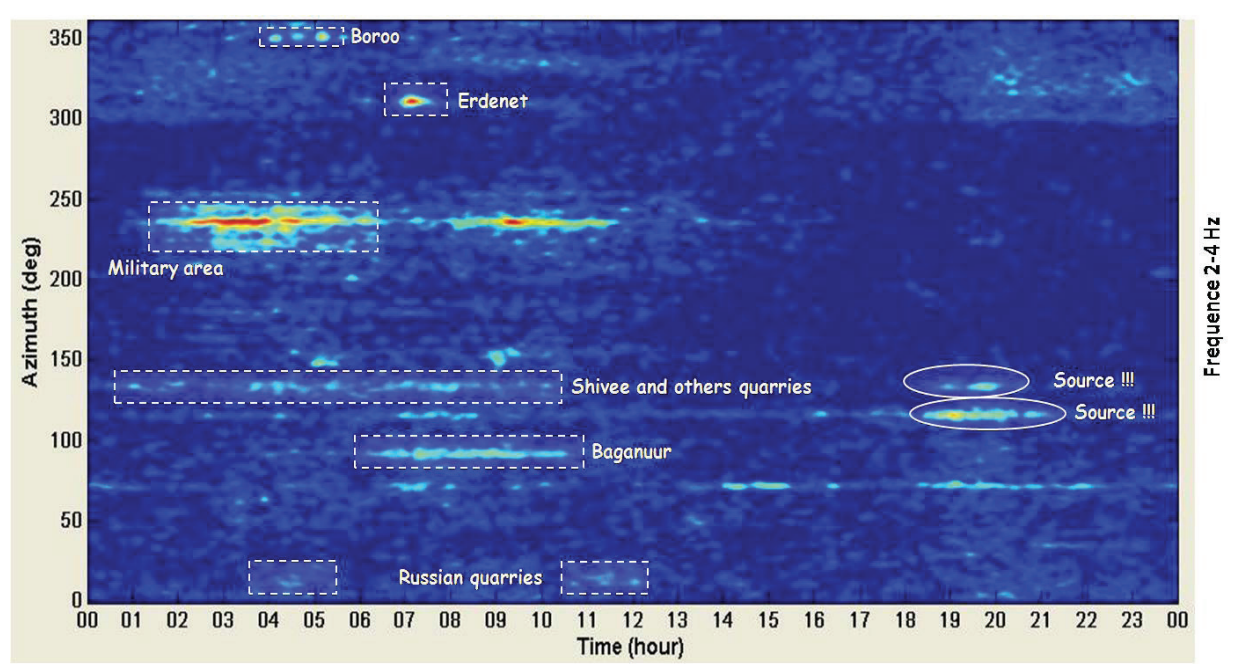

Figure 6 Determined detail source by high frequencies (2-4 Hz) in atmospheric.

We have possibility to determine detail source by high and low frequencies (HF 0.1-5, BF 0.001-01, Hz) in atmosphere (figure 6). Sound wave's amplitude of recorded from mining explosion is about 0.005-0.027 Pa RMS, but in summer time it is about 5-10 $\mathrm{mPa}$ RMS. Therefore we observed recorded signals are related by seasonal variation and wind direction of atmosphere. The sound velocity is about standard $(310-350 \mathrm{~km} / \mathrm{s})$ by analysis $\mathrm{PMCC}^{3}$ (Progressive Multi-Channel Correlation; Y. Cansi, 1995) and 250-280 km/s by manual interpretation.

\section{lous}

Infrasound wave propagation anoma-

The Baganuur mining site works actively in four seasons. In the recorded sound signal of mining explosion in infrasound stations, there have not closely manual pick-up phases (troposphere $\boldsymbol{l} \boldsymbol{w}^{\mathbf{4}}$, stratosphere $\left.\boldsymbol{l} \boldsymbol{s}\right)$ to the average velocity table by Brown (Mean celerity from [Brown, 2002]). It shows that observed anomaly for primary wave $(\boldsymbol{l} \boldsymbol{w})$. The model of sound wave's

3 PMCC-Progressive Multi-Channel Correlation $4 \mathrm{Iw}$ tropospheric phase $(0-10 \mathrm{~km})$ propagation velocity is not adjusted in local distance less than $150 \mathrm{~km}$. It's not observed for all other explosion's areas except Baganuur (figure 7). Because of it's not primary wave, there are two phases $\underline{\boldsymbol{l} \boldsymbol{s}}$ an $\boldsymbol{l t}$ which are recorded from refraction waves from the atmosphere layer more than $40 \mathrm{~km}$. There have recorded $\boldsymbol{l} t$ sound velocity phase of thermosphere with $\sim 250-280$ $\mathrm{km} / \mathrm{s}$ in winter time and $\underline{\boldsymbol{l}}$ phases with velocity $\sim 260-340 \mathrm{~km} / \mathrm{s}$ in summer time. The variation of sound velocity in atmosphere is observed in two mining sites. 


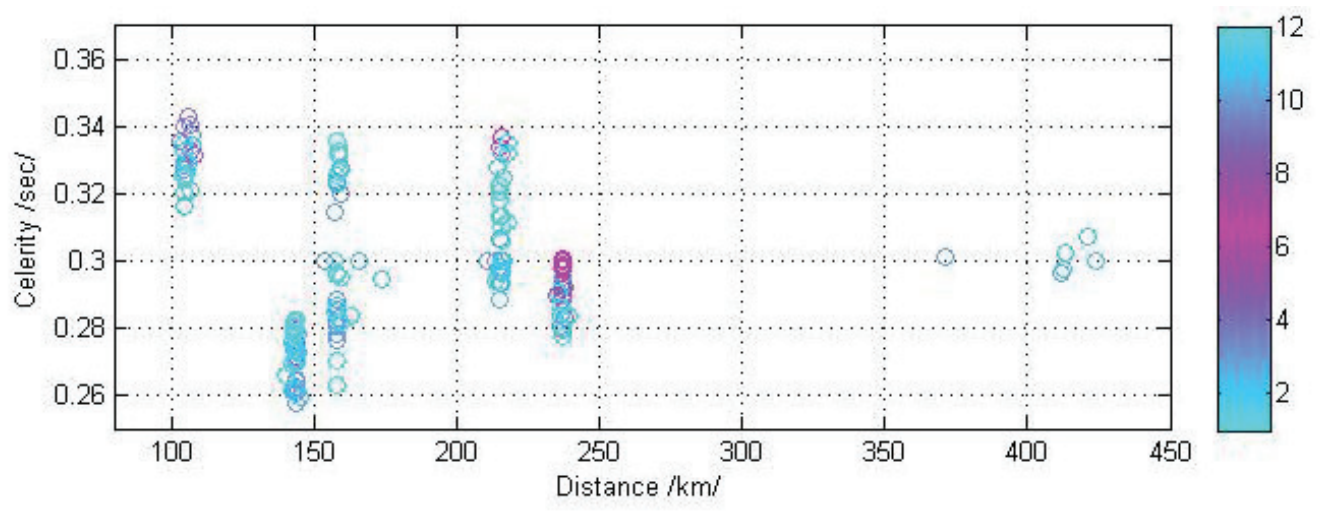

\section{Review of the phase mean celerities}

\begin{tabular}{|l|c|c|c|}
\hline \multicolumn{1}{|c|}{ Phase } & Nomenclature & $\begin{array}{c}\text { Mean celerity from } \\
\text { [Brown, 2002] }\end{array}$ & $\begin{array}{c}\text { Mean celerity from } \\
\text { tables }\end{array}$ \\
\hline Tropospheric phase & Iw $<20 \mathrm{~km}$ & $\sim 340$ & $320-360$ \\
\hline Stratospheric phase & Is $<60 \mathrm{~km}$ & $280-310$ & $230-325$ \\
\hline Thermospheric phase & It $>60 \mathrm{~km}$ & $250-280$ & $200-330$ \\
\hline
\end{tabular}

Figure 7 Result of low celerity an average C 0.250-0.280 (red circle Baganuur quarry blast) Mean celerity table from [Brown, 2002]

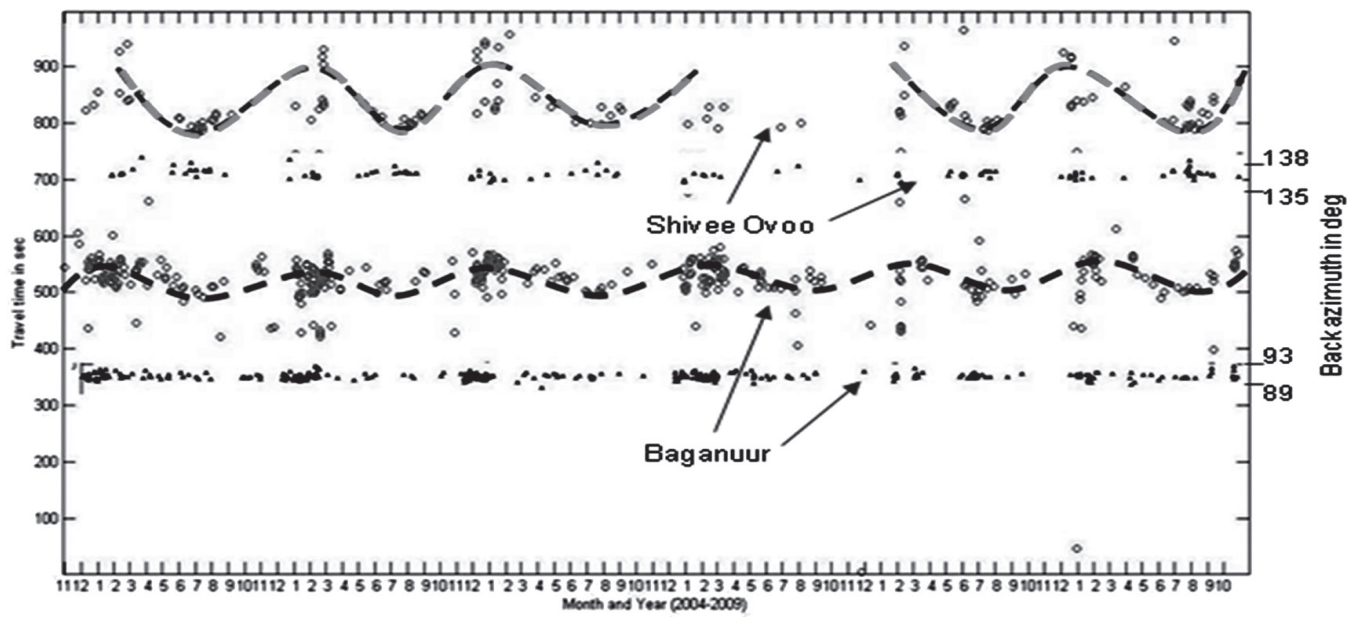

Figure 8 Relocation of the selected signals detected by array. Shivee-Ovoo celerity range $\sim 260-340 \mathrm{~m} /$ sec corresponding stratospheric return Is, More diurnal and seasonal variation. Baganuur celerity range $\sim 250-320 \mathrm{~m} / \mathrm{sec}$ corresponding stratospheric, thermospheric return Is, It. Cyclical variation by season, which increased up to $320 \mathrm{~m} / \mathrm{sec}$ in summer to $250 \mathrm{~m} / \mathrm{sec}$ in winter. 
We compared all manual measurements of infrasound travel-time, celerity and azimuth from Baganuur (143 km), Erdenet (216 $\mathrm{km})$, Sharyn gol (157 km), Shivee ovoo (237 $\mathrm{km})$ and Boroo $(104 \mathrm{~km})$ mining sites at each month. The observed travel time variation of about 50-100 seconds is mainly due to seasonal dependence of atmospheric wind characteristics (figure 8). The wind direction of Mongolia dominates in direction NW-SE. The windiest season is during March to April in the Mongolia (reference). The number of recorded acoustic signals of quarry blast from mining sites of Baganuur, Erdenet, Boroo, and Sharyn gol is decreasing in spring associated with unfavorable wind direction during summer. On the contrary, the recorded acoustic signal of Shivee-Ovoo quarry blats is increasing in summer time during from June to September by corresponding decreasing of wind force and changement of wind direction.

\section{Conclusion}

This study provides further confirmation that short-range sound propagation depends strongly on the atmospheric conditions, primarily on the variability of the meridional and zonal winds. In winter, infrasonic waves propagate both in the stratosphere and in the thermosphere sound channels. In summer, the propagation model explains only reflections in the thermosphere. In Shivee-Ovoo celerity varies cyclical between $260 \mathrm{~m} / \mathrm{s}$ in November and $340 \mathrm{~m} / \mathrm{s}$ in October. Detection rate also changes by season and over all detection in rate is about $40.8 \%$. Almost all the first arrivals reached to Baganuur along the continental path are stratospheric return phases Is.

In Baganuur celerity changes with the rate of $250-300 \mathrm{~m} / \mathrm{s}$ which corresponds to stratospheric and thermospheric return phases $(I s-I t)$. Detection rate $(41.1 \%)$ is relatively consistent throughout the year and slightly low in summer variation by season. This increased up to $320 \mathrm{~m} / \mathrm{s}$ in summer to $260 \mathrm{~m} / \mathrm{s}$ in winter. There were no predicted returns from the stratosphere when the propagation direction was against the predominant stratospheric winds. No attempt was done to predict scattered waves or tropopause ducted waves diffracted inside the shadow-zone. This type of surface guided waves depends strongly on the tropospheric wind field, which may be highly variable.

\section{References}

1. Alcoverro, B. (1998). "Proposition d'un systeme de filtrage acoustique pourune station infrason IMS," CEA-DASE Scientific Report No. 241.

2. Bayarsaikhan. $\mathrm{Ch}^{1}$, A. Le Pichon ${ }^{2}, \mathrm{M}$. Ulziibat'., O.Sebe ${ }^{2}$ (2005) "Seismo-Acoustic data analysis at I34MN Mongolia "Infrasound Technology Workshop PAPEETE - TAHITI -FRENCH POLYNESIA NOVEMBER 28 - DECEMBER 2, 2005,

3. Brown, D. J., C. N. Katz, R. Le Bras, M. P. Flanagan, J. Wang, and A. K. Gault, Infrasonic signal detection and source location at the Prototype Data Centre, Pure Appl. Geophys., 159, 1081-1125, 2002.

4. Cansi, Y. (1995). "An automatic seismic event processing for detection and location: The PMCC method," Geophys. Res. Lett. 22, 1021-1024.

5. Donn.W.L, Rind.D (1972) "Microbaroms and the Temperature and Wind of the upper Atmosphere" Journal of atmospheric sciences. Vol 29: 158-159

6. Evers and Haak (2007) Infrasonic forerunners: Exeptionally fast acoustic phases// Geophys Res Lett. 34:L10806. doi: 10.1029/2007GL029353

7. Sorrells, G.G., J.G Swaso and I Tibuleac, (2000). Seismo-Acoustic Studies at the Nevada Seismic Array," Proceedings of the $22^{\text {nd }}$ Seismic Research Symposium (this volume). 